\title{
DINÂMICA E CARACTERÍSTICAS DA PRODUÇÃO DE BOVINOS PARA AUTOCONSUMO EM SANTA CATARINA
}

\author{
DYNAMICS AND CHARACTERISTICS OF CATTLE PRODUCTION FOR \\ SELF-CONSUMPTION IN SANTA CATARINA
}

\author{
DINÁMICA Y CARACTERÍSTICAS DE LA PRODUCCIÓN GANADERA PARA \\ AUTO CONSUMO EN SANTA CATARINA
}

\author{
Alexandre Luís Giehl ${ }^{1}$ \\ https://orcid.org/0000-0002-3897-7007 \\ Marcia Mondardo 2 \\ https://orcid.org/0000-0002-1775-2327
}

Submissão: 30/11/2020 / Aceito: 22/02/2021 / Publicado: 31/03/2021.

\begin{abstract}
Resumo
A produção de bovinos para autoconsumo representa importante fonte de alimentos e de renda para mais de 50 mil agricultores catarinenses, gerando um valor bruto anual de $\mathrm{R} \$ 223$ milhões. Apesar da relevância econômica e social, há poucos estudos sobre o tema que não é abrangido pela maioria das estatísticas oficiais. Este artigo apresenta uma análise exploratória dos abates de bovinos para autoconsumo em Santa Catarina entre 2010 e 2019, identificando as principais características e avaliando as mudanças ocorridas no período. Foram utilizados dados do cadastro de produtores e animais junto ao órgão de defesa agropecuária do estado. Verificou-se que, em 2010, o autoconsumo representava $17,7 \%$ do total de bovinos abatidos em Santa Catarina, índice que caiu para 13,5\% em 2019. Observouse predominância no abate de machos (52,3\% em 2019), embora a participação de fêmeas tenha crescido entre 2014 e 2019. Quanto à idade, há concentração de abate de animais acima de 36 meses (38,6\% em 2019), seguida por animais de 13 a 24 meses (32,0\%). A Mesorregião Oeste Catarinense foi responsável por $67,7 \%$ dos abates realizados em 2019, embora concentre apenas 47,4\% do rebanho bovino estadual. O mês de maior ocorrência de abates é dezembro, seguido por abril, coincidindo com as festas de final de ano e a Páscoa, respectivamente. É possível afirmar que, não obstante a baixa visibilidade, o abate de bovinos para autoconsumo tem relevância econômica e social no meio rural catarinense, ainda que com diferenças regionais e variações sazonais.
\end{abstract}

Palavras-chave: Bovinos. Autoconsumo. Agricultura familiar. Carne bovina. Segurança alimentar.

\footnotetext{
${ }^{1}$ Eng.-agr., Analista de socioeconomia e desenvolvimento rural - Centro de Socioeconomia e Planejamento Agrícola/Empresa de Pesquisa Agropecuária e Extensão Rural de Santa Catarina. E-mail: alexandregiehl@epagri.sc.gov.br

${ }^{2}$ Mestre, Agente de apoio à pesquisa e extensão (Estatístico) - Centro de Socioeconomia e Planejamento Agrícola/Empresa de Pesquisa Agropecuária e Extensão Rural de Santa Catarina. E-mail: mmondardo@epagri.sc.gov.br
} 


\begin{abstract}
The production of cattle for self-consumption represents an important source of food and income for more than 50 thousand farmers in Santa Catarina, generating a gross annual value of R $\$ 223$ million. Despite the economic and social relevance, there are few studies about this topic and it is not covered by most official statistics. This article presents an exploratory analysis of cattle slaughter for self-consumption in Santa Catarina between 2010 and 2019, to identify the main characteristics and evaluate the changes that occurred in the period. We used data from the register of producers and animals from the state's agricultural defense agency. According the study, in 2010 self-consumption represented $17.7 \%$ of the total number of cattle slaughtered in Santa Catarina, an index that dropped to $13.5 \%$ in 2019. There was a predominance in the slaughter of males (52.3\% in 2019), although the participation of females increased between 2014 and 2019. As for age, there was a concentration in the slaughter of animals over 36 months (38.6\% in 2019), followed by animals from 13 to 24 months $(32.0 \%)$. The Oeste Catarinense mesoregion was responsible for $67.7 \%$ of the slaughtering carried out in 2019, although it concentrates only $47.4 \%$ of the state cattle herd. The month with the highest occurrence of slaughter is December, followed by April, coinciding with the end of the year and Easter celebrations, respectively. Despite the low visibility, the slaughter of cattle for self-consumption has economic and social relevance in rural spaces from Santa Catarina, although with regional and seasonal variations..
\end{abstract}

Keywords: Cattle. Self-consumption. Family farming. Beef. Food security.

\title{
Resumen
}

La producción de ganado para autoconsumo representa una importante fuente de alimentación y ingresos para más de 50 mil agricultores de Santa Catarina, generando un valor bruto anual de 223 millones de reales. A pesar de la relevancia económica y social, hay pocos estudios sobre el tema y no está cubierto por la mayoría de las estadísticas oficiales. Este artículo presenta un análisis exploratorio de la matanza de ganado para autoconsumo en Santa Catarina entre 2010 y 2019, identificando las principales características y evaluando los cambios ocurridos en el período. Se utilizaron datos del registro de la agencia estatal de defensa sanitaria animal. En 2010, el autoconsumo representaba el 17,7\% del total de ganado sacrificado en Santa Catarina, tasa que se redujo al 13,5\% en 2019. Predominó la matanza de machos (52,3\% en 2019), aunque la participación de hembras aumentó entre 2014 y 2019. También si observó concentración en la matanza de animales mayores de 36 meses (38,6\% en 2019) y animales de 13 a 24 meses (32,0\%). La mesorregión Oeste Catarinense fue responsable del 67,7\% de las matanzas en 2019, aunque concentra solo el 47,4\% del rebaño bovino del estado. El mes con mayor ocurrencia de matanzas es diciembre, seguido de abril, coincidiendo con el fin de año y las celebraciones de Semana Santa, respectivamente. No obstante la baja visibilidad, la matanza de ganado para el autoconsumo tiene relevancia económica y social en la zona rural de Santa Catarina, aunque con diferencias regionales y estacionales.

Palabras clave: Ganado. Autoconsumo. Agricultura familiar. Carne de vaca. Seguridad alimentaria.

\section{INTRODUÇÃO}

Santa Catarina destaca-se na produção agropecuária brasileira, ocupando a $9^{a}$ posição no ranking de Valor Bruto da Produção Agropecuária - VBP (MAPA, 2020), embora seja a 
$20^{\mathrm{a}}$ unidade da federação em termos de área. Tal posição deve-se, principalmente, ao valor agregado das principais atividades desenvolvidas no meio rural catarinense, como a produção animal, responsável por 56,77\% do VBP total em 2018 (TORESAN et al., 2019).

Embora o estado seja mais conhecido pela produção de frangos e suínos, responsáveis por cerca de $35 \%$ do VBP, os bovinos também têm relevância na geração de receitas agropecuárias em Santa Catarina. Em 2018, o VBP do leite foi de R \$ 3,46 bilhões e o da carne bovina de $\mathrm{R} \$ 1,54$ bilhão, ocupando a $3^{\mathrm{a}}$ e a $6^{\mathrm{a}}$ posição no ranking estadual, respectivamente (TORESAN et al., 2019).

Ainda em relação aos bovinos, em 2019 o rebanho estadual era formado por 4,70 milhões de cabeças, distribuídas entre aproximadamente 73 mil produtores de 293 municípios, de um total de 295 (GIEHL, 2020a). Nesse mesmo ano, foram abatidos 750,7 mil bovinos no estado.

Estudo realizado por Giehl e Mondardo (2019) categorizou os produtores de bovinos segundo o número de animais vendidos a estabelecimentos de abate inspecionados no ano de 2017. De acordo com os autores, a maioria dos produtores catarinenses era de pequena escala: 77,51\% destinaram de 1 a 9 animais para abate naquele ano. O estudo ressalta ainda que muitos desses são produtores de leite, sendo os abates relativos aos animais eliminados do rebanho. No mesmo trabalho, identificou-se uma significativa concentração na produção de carne bovina do estado: embora representassem mais de $3 / 4$ do total, os produtores com menos de 10 bovinos destinados ao abate respondiam por apenas $15,01 \%$ dos animais abatidos em 2017. No outro extremo, aqueles com 1.000 ou mais animais abatidos no ano, que perfaziam $0,12 \%$ dos criadores, responderam por $13,18 \%$ da produção.

Ainda em relação ao perfil da bovinocultura catarinense, Giehl et al. (2019) demonstraram que, do total de produtores que comercializaram animais para abate em estabelecimentos inspecionados em 2017, 58,38\% eram agricultores familiares. Esses produtores foram responsáveis por $27,86 \%$ dos animais abatidos naquele ano. Isso demonstra que, embora seja uma atividade normalmente mais associada a grandes propriedades, a bovinocultura catarinense contempla um significativo contingente de produtores familiares.

De acordo com os dados apresentados por Giehl (2020a), dos 750,7 mil bovinos abatidos em Santa Catarina em 2019, 101,5 mil (13,52\%) destinaram-se ao autoconsumo, o que indica que o abate desses animais foi realizado no próprio estabelecimento agropecuário. 
Essa modalidade de abate possui também uma relevante participação econômica no meio rural. Do VBP total da bovinocultura catarinense em 2018 (R\$ 1,5 bilhão), R\$ 223 milhões $(14,48 \%)$ são oriundos dos abates para autoconsumo (GIEHL, 2018). Também chama atenção o número de produtores que realizam o abate para autoconsumo: cerca de 50 mil em 2019, ou mais de 1/4 dos estabelecimentos agropecuários do estado.

Apesar desses números expressivos, as abordagens acadêmicas com viés econômico que tratam da pecuária costumam se concentrar nos aspectos relacionados ao mercado formal, seja a partir da produção primária ou, mais frequentemente, das agroindústrias. Pouca atenção é dispensada à relevância dessa atividade produtiva na segurança alimentar das famílias produtoras e tampouco para sua importância socioeconômica.

Além disso, o abate para consumo próprio não faz parte da maioria das estatísticas oficiais, o que contribui com a invisibilização da atividade. Em Santa Catarina, essa situação se faz sentir de forma significativa. Embora a produção de bovinos seja uma das atividades mais expressivas no que diz respeito ao número de produtores, percebe-se certa subvalorização da mesma, em especial do segmento de produção de carne, o que se reflete em poucos estudos no âmbito estadual que se proponham à compreensão da sua dinâmica social e econômica. Quando voltamos o olhar para o autoconsumo, as lacunas são ainda mais expressivas.

Tendo em vista o exposto, o presente artigo apresenta uma análise exploratória dos dados sobre o abate de bovinos para autoconsumo em Santa Catarina ao longo de um período de 10 anos, buscando identificar as principais características dessa modalidade, avaliar a sua evolução e compreender alguns aspectos relacionados a sua dinâmica, bem como contribuir com a inclusão desse tema no debate acadêmico.

\section{PRODUÇÃO DE BOVINOS PARA AUTOCONSUMO: TRAJETÓRIA E RELAÇÕES}

A pecuária catarinense se desenvolveu primeiramente na Região Serrana, principalmente em função da presença de pastagens nativas. (WEDEKIN, 2017). Posteriormente, a atividade se expandiu para outras partes do território estadual. A partir de meados dos anos 1980, a bovinocultura ganhou grande impulso na Região Oeste, principalmente em função da expansão da produção de leite. Com isso, entre 1985 e 2002 a 
participação da região na produção estadual passou de $45 \%$ para $64 \%$ (SANTOS; MARCONDES; CORDEIRO, 2006).

Segundo análises empíricas de diversos atores sociais ligados à cadeia da pecuária, a expansão da produção leiteira na Mesorregião Oeste Catarinense é um dos fatores que ajudam a explicar sua expressiva participação na produção estadual de carne bovina, sendo responsável por 49,95\% dos animais abatidos no estado em 2019 (GIEHL, 2020a). Contudo, essa "hipótese" carece de análises mais embasadas, já que tem sido relatada a expansão da criação de bovinos com finalidade exclusiva de corte em diversos municípios da região.

Em relação ao perfil da pecuária catarinense, Fachin (2014) ressalta que a atividade se desenvolveu de maneira bastante heterogênea, caracterizando-se pelo contraste entre propriedades altamente tecnificadas, que contam com gestão profissional, e outra parcela em que predomina o sistema extensivo e com reduzido uso de tecnologias, o que resulta em baixos índices zootécnicos. Há que se considerar também as diferentes finalidades do rebanho, o que acaba por conformar um modelo misto, em que vários perfis de produtores coexistem.

Dentre esses perfis, um contingente significativo tem como uma das finalidades da criação de bovinos a obtenção de carne para consumo próprio. Em alguns casos, o autoconsumo é o objetivo central, embora o mais comum é que seja uma finalidade complementar, em que o abate de animais para consumo próprio é percebido como um "subproduto" de outra atividade principal, como a bovinocultura de leite ou mesmo a bovinocultura de corte comercial.

Segundo Lovisolo (1989), o autoconsumo constitui-se numa renda não monetária, obtida por meio da redução dos dispêndios com a compra de determinados gêneros alimentícios, auxiliando na estabilidade socioeconômica das unidades. Ou seja, caso não houvesse a produção para autoconsumo, os alimentos precisariam ser adquiridos a preços de mercado. Ainda de acordo com o autor, essa prática pode ser vista como um mecanismo que possibilita economizar recursos para investir em outros bens na unidade produtiva.

Grisa, Schneider e Conterato (2013) vão além ao afirmarem que uma das principais funções da produção para autoconsumo é a garantia da autossuficiência alimentar da família e da unidade produtiva. Ressaltam que esse tipo de produção cumpre um importante papel ao internalizar a satisfação de uma das necessidades vitais das famílias, a alimentação. Além 
disso, em determinados contextos, o autoconsumo tem uma função de preservação da cultura, dado que muitas das práticas são repassadas de pais para filhos, apontam os autores.

Contudo, como bem descreve Fontoura (2012), por algum tempo considerou-se a produção para autoconsumo uma atividade atrasada e antieconômica, não sendo merecedora da atenção da academia por sua suposta irrelevância. Esse cenário apresentou algumas mudanças a partir dos anos 1990 e, principalmente, 2000, quando são publicados inúmeros trabalhos com tal temática.

Não obstante a recente valorização do tema, diversos estudos realizados nesse período demonstraram queda na participação do autoconsumo na produção total das propriedades rurais. Em pesquisa desenvolvida em quatro regiões do Rio Grande do Sul, Grisa (2007) indica que a produção para o consumo familiar era maior e mais diversificada em períodos anteriores, havendo uma diminuição nesse tipo de atividade em prol da ampliação dos cultivos comerciais. Gazolla (2004) também aponta uma redução nesse perfil de produção, devido, principalmente, ao processo de mercantilização da agricultura familiar, com incentivos diversos à especialização desse segmento.

A menor presença não significa, contudo, que tal modalidade produtiva não possua mais importância no meio rural, principalmente no contexto da agricultura familiar. Ela continua sendo fundamental para a reprodução social das unidades familiares. É o que evidencia, por exemplo, o estudo de Grisa (2007). A autora demonstrou que o autoconsumo representava, em média, $27,24 \%$ da renda total das unidades familiares pesquisadas, variando de $16,73 \%$ a $38,34 \%$.

Reforçando a relevância dessa modalidade, Grisa e Conterato (2011), a partir de dados do Censo Agropecuário de 2006, demonstraram que 3,84 milhões de estabelecimentos rurais brasileiros apresentavam produção para autoconsumo, o que significa que 74,09\% do total possuíam tal estratégia de reprodução social. Infelizmente, o Censo Agropecuário de 2017 não permite obter tais informações a partir dos dados disponibilizados pelo IBGE. O referido Censo informa apenas o número de estabelecimentos que têm o consumo próprio como principal finalidade (2,05 milhões ou 40,40\% do total), mas não o total dos que se utilizam dessa estratégia, mesmo que de forma secundária.

Fontoura (2012) destaca que, além dos aspectos econômicos já mencionados, a produção para autoconsumo também contribui para a autonomia das famílias, colabora com 
a segurança alimentar e nutricional, estreita os laços de amizade através da reciprocidade e pode colaborar para a diminuição da pobreza rural.

Numa perspectiva semelhante, Grisa, Schneider e Conterato (2013) apontam outro papel de destaque da produção para autoconsumo: parte dos produtos é destinada a trocas e/ou doações para vizinhos, parentes e amigos, sendo comum o intercâmbio de sementes, mudas, frutas, pedaços de carne, entre outros. Segundo os autores, no passado essas trocas possuíam uma utilidade prática, já que a dificuldade de acesso a meios de conservação eficientes, tornava esse um bom mecanismo de garantia do abastecimento alimentar ao longo do ano. Atualmente, esse ato constitui-se numa forma de sociabilidade e reciprocidade.

Não obstante a existência de um conjunto expressivo de estudos sobre produção para autoconsumo na atualidade, eles normalmente não se aprofundam (ou, por vezes, ignoram) a produção animal e suas especificidades, sendo difícil encontrar trabalhos que adotem tal foco. Essa situação acaba por dificultar uma efetiva percepção da importância dessas atividades na reprodução social dos agricultores brasileiros, em especial no caso da agricultura familiar.

Para que se tenha noção da relevância dessa estratégia no âmbito da produção animal e, mais especificamente, na bovinocultura, estudo realizado por Miranda e Zen (2019) demonstrou que, em 2015, o autoconsumo de carne bovina no Brasil foi equivalente a 2,46 milhões de animais. De acordo como os dados do IBGE, naquele ano foram abatidos 30,65 milhões de bovinos em abatedouros inspecionados. Com isso, verifica-se que o autoconsumo representou $7,42 \%$ dos abates.

Apesar desses resultados expressivos e da importância que as rendas não monetárias têm para os orçamentos familiares, Miranda e Zen ressaltam que elas não são computadas na maioria das estatísticas governamentais (como no cálculo do PIB, por exemplo), seja por dificuldade de mensurá-las ou por percepções equivocadas em relação à sua amplitude.

\section{METODOLOGIA}

Os dados analisados no presente estudo são oriundos do Sistema de Gestão da Defesa Agropecuária Catarinense (Sigen), desenvolvido e utilizado pela Companhia Integrada de Desenvolvimento Agrícola de Santa Catarina (Cidasc), órgão estadual de sanidade e vigilância animal e vegetal. 
De acordo com a estratégia de defesa sanitária animal de Santa Catarina, todos os bovídeos do estado devem, obrigatoriamente, estar registrados junto à Cidasc e portar brincos com um número de identificação individual, que os vincula a uma Unidade de Exploração Pecuária $(\mathrm{UEP})^{3}$.

No caso da morte de animais na propriedade, seja em decorrência de morte natural, acidente ou abate para consumo próprio, a legislação estadual estabelece que o produtor deve informar tal fato à Cidasc e realizar a "Atualização de saldo de animais", procedimento por meio do qual os animais mortos ou abatidos são excluídos de seu cadastro, ficando essa informação registrada no sistema. No presente estudo, foram utilizados os dados de atualização de saldo de animais registrados no Sigen, referentes ao período de 2010 a 2019.

Para a análise crítica e sistematização das informações do estado nos níveis de anos, período de registro e categoria de animais, utilizou-se o software SAS 9.4 (Statistical Analysis System), por meio do qual foram geradas as informações agregadas apresentadas e analisadas na seção seguinte. Por se tratarem de informações censitárias e individualizadas para cada abate realizado no período, não foram realizadas inferências estatísticas.

\section{RESULTADOS E DISCUSSÃO}

A cada ano, cerca de 50 mil produtores abatem bovinos para consumo próprio em suas propriedades rurais. Esse montante representa 27,6\% dos 183 mil estabelecimentos agropecuários existentes em Santa Catarina, de acordo com o Censo Agropecuário de 2017. A Figura 1 apresenta a evolução desse número entre 2013 e $2019^{4}$.

\footnotetext{
${ }^{3}$ A ausência de registro junto à Cidasc de animais nascidos nas propriedades rurais, dentro do prazo estipulado pelas normas, pode resultar em apreensão e abate sanitário do(s) mesmo(s), além de multa e outras sanções. Da mesma forma, a falta de registro do abate ou morte de bovídeos pode resultar em multa, em caso de fiscalização por parte do órgão. Para maiores informações sobre os procedimentos operacionais para controle da identificação, movimentação e abate de bovinos e bubalinos em Santa Catarina, consultar a Instrução de Serviço no $\quad 006 / 2019 \quad$ - DEDSA/DEINP, disponível no seguinte endereço:
} www.cidasc.sc.gov.br/defesasanitariaanimal/programas/rastreabilidade-bovina-e-bubalina/.

${ }^{4}$ Para este parâmetro, não há dados disponíveis para o período de 2010 a 2012. 
Figura 1 - Quantidade de produtores que realizaram abate de bovinos para autoconsumo, por ano - Santa Catarina - 2013/2019

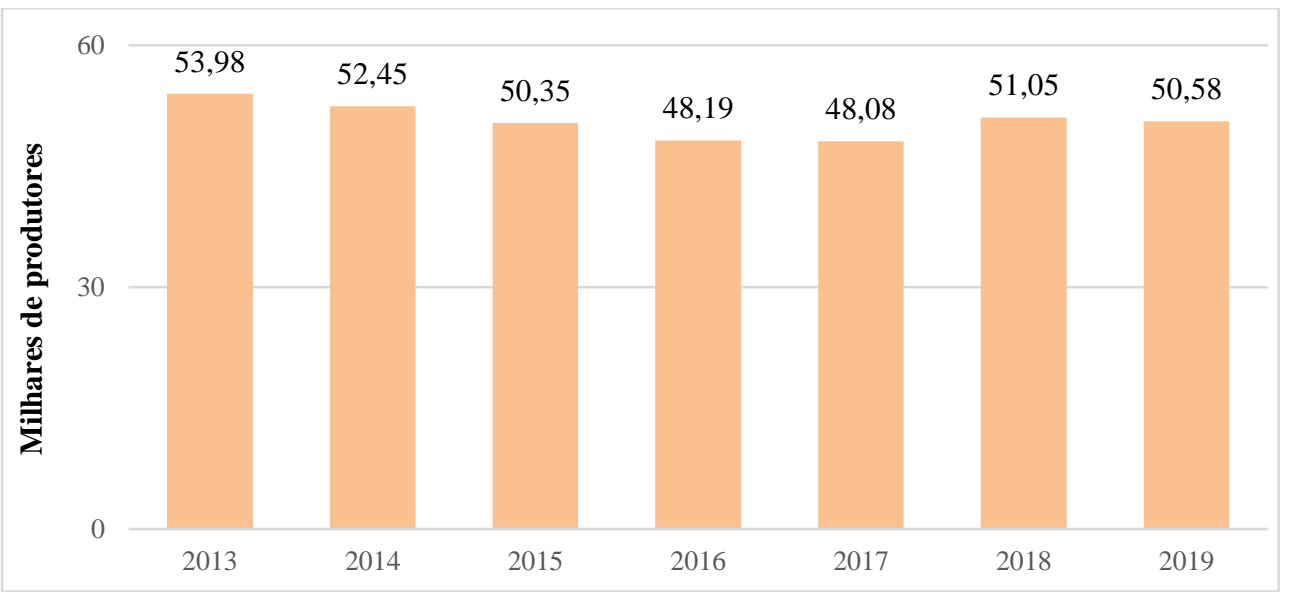

Fonte: Elaborado pelos autores, a partir de dados da Cidasc.

O número de produtores que abateram bovinos para autoconsumo em 2019 (50,6 mil) foi superior ao daqueles que destinaram animais para abate em estabelecimentos inspecionados (36,4 mil). É claro que, nesses dois grupos, observam-se inúmeras sobreposições, mas o objetivo da comparação é simplesmente demonstrar a abrangência dessa atividade, sem adentrar nos pormenores do perfil dos produtores.

Comparando os anos de 2013 e 2019, percebe-se uma redução de 6,30\% no número de produtores, com oscilações no período intermediário. Como fica evidenciado no gráfico, a tendência de queda foi parcialmente revertida em 2018. Apesar de nova redução em 2019 ($0,9 \%$ ), não é possível afirmar que o movimento de queda vá ser efetivamente retomado nos próximos anos. É importante frisar que parte das variações observadas deve-se a fatores conjunturais relacionados ao mercado e às características dessa estratégia de reprodução social, como veremos mais detalhadamente adiante. Além disso, é preciso levar em consideração que o número total de estabelecimentos agropecuários tem apresentado queda nos últimos anos (-5,5\% entre 2006 e 2017, segundo os dois últimos censos agropecuários), o que explicaria parte da variação no número de produtores que realizaram autoconsumo.

Em estudo realizado com pecuaristas de corte do Rio Grande do Sul, Matte e Waquil (2013) apontam diversos fatores responsáveis pela vulnerabilidade social desse público, como é o caso do envelhecimento, da dificuldade de obtenção de força de trabalho nas propriedades rurais e da ausência de sucessores, entre outros. Segundo os autores, dentre outras consequências, a falta de mão de obra interfere no cultivo de lavouras com finalidade 
de autoconsumo. Os autores afirmam ainda que atividades desse tipo têm "continuidade incerta na medida em que há um avanço na idade dos membros que permanecem no estabelecimento e o consumo interno reduz" (MATTE; WAQUIL, 2013, p. 121). Embora o artigo se refira às chamadas "lavouras de subsistência", podemos extrapolar essas dificuldades para a produção pecuária. No caso dos bovinos, isso se torna mais explícito, já que a quantidade de carne obtida de cada animal abatido, embora varie de acordo com idade, sexo e raça, normalmente supera uma ou duas centenas de quilogramas. Se num contexto de famílias numerosas essa era uma característica desejável, a situação ganha novos contornos com a redução no tamanho dos núcleos familiares. Além da diminuição na demanda de carne, a limitada disponibilidade de força de trabalho para o manejo dos animais também afeta as decisões em torno da produção para autoconsumo, podendo resultar na redução do número de animais destinados a tal fim ou, em última instância, no abandono dessa atividade.

Corroborando as afirmações anteriores, estudo realizado pro Dorigon et al. (2020) em 112 municípios do Oeste Catarinense concluiu que a falta de mão de obra $(23,9 \%)$ é a principal razão apontada pelos que declararam deixar de produzir algum tipo de carne para autoconsumo, seguida por falta de área $(13,1 \%)$ e pelo fato de deixarem de consumir esse produto $(5,8 \%)$.

Uma das formas de superar parte dos entraves resultantes da redução no tamanho das famílias é a estratégia da reciprocidade. Em seu estudo, realizado no oeste do Rio Grande do Sul, Fontoura (2012) ressalta que ainda existe a prática da troca de produtos entre vizinhos, mas em menor intensidade do que ocorria há algumas décadas. "Antigamente, eu abatia e doava um pedaço de carne, depois era retribuído com a mesma peça”, relata um dos entrevistados. De acordo com outro entrevistado, "quando eu carneio dou para os vizinhos um quarto, uma paleta [...] e quando o vizinho carneia devolve o mesmo pedaço". No presente estudo não foi possível adentrar nesse tipo de análise, o que nos impossibilita de avaliar o impacto das relações de reciprocidade no autoconsumo em Santa Catarina.

Quando partimos para a análise do número de animais abatidos para autoconsumo, verifica-se uma queda de 12,16\% entre 2010 e 2019 (Tabela 1). As maiores reduções são observadas entre os anos de 2010 e 2013, com relativa estabilização entre 2014 e 2017.

Em 2013, registrou-se o menor número de abates para autoconsumo da série histórica analisada. Contudo, é necessário destacar que, naquela oportunidade, foram realizadas alterações no Sigen, o que pode ter prejudicado o registro e a obtenção de alguns dados, 
afetando os resultados finais. Por isso, a utilização de informações daquele ano demanda ressalvas.

Tabela 1 - Bovinos abatidos por ano e por modalidade de abate - Santa Catarina - 2010/2019

\begin{tabular}{cccc}
\hline Ano & Abate inspecionado (cab.) & Autoconsumo (cab.) & Abate total (cab.) \\
\hline 2010 & 537.028 & 115.523 & 652.551 \\
2011 & 521.326 & 103.530 & 624.856 \\
2012 & 492.892 & 95.720 & 588.612 \\
2013 & 500.829 & 87.400 & 588.229 \\
2014 & 540.662 & 97.734 & 638.396 \\
2015 & 546.455 & 95.285 & 641.740 \\
2016 & 529.962 & 92.114 & 622.076 \\
2017 & 550.576 & 95.963 & 646.539 \\
2018 & 612.354 & 104.091 & 716.445 \\
2019 & 649.190 & 101.471 & 750.661 \\
\hline
\end{tabular}

Fonte: Elaborado pelos autores, a partir de dados da Cidasc.

Conforme evidencia a Tabela 1, em 2017 e 2018 observaram-se aumentos expressivos no número de animais abatidos para autoconsumo, após um período de quedas. Em 2019, por outro lado, registrou-se nova queda. É importante destacar que no último trimestre desse ano ocorreram expressivas elevações nos preços do boi gordo, o que pode ter estimulado muitos produtores a comercializarem animais que, anteriormente, seriam destinamos ao consumo familiar. Essa questão será melhor abordada adiante.

A partir das informações da Figura 1 e da Tabela 1, calculou-se o número médio de bovinos abatidos anualmente por produtor, com finalidade de autoconsumo. Esse índice, que em 2013 era de 1,62, cresceu ao longo do período analisado, atingindo 2,01 em 2019. Tal variação é decorrente tanto do aumento no número de abates, quanto da queda no total de produtores. Para que se tenha uma ideia do significado financeiro desses números, levandose em consideração o peso médio de abate dos animais e o preço médio de atacado da carne bovina em 2019, o valor para aquisição de volume semelhante de carne seria superior a $\mathrm{R} \$ 6$ mil. É claro que uma análise mais refinada demandaria identificar a moda, de forma a avaliar o tipo de situação predominante, bem como considerar as especificidades regionais. De qualquer forma, os cálculos anteriores permitem uma noção inicial da importância econômica dessa estratégia produtiva.

Em relação à participação do autoconsumo no total de abates realizados em Santa Catarina (Figura 2), verificam-se percentuais expressivos, mas declinantes ao longo do período analisado. Além das oscilações no número de animais abatidos para consumo 
próprio, outro fator que contribuiu para esses resultados é o crescimento nos abates inspecionados. Vale destacar que a produção catarinense de carne bovina atende pouco mais de $50 \%$ do consumo estadual, o que indica a disponibilidade de mercado consumidor para os eventuais acréscimos de produção (GIEHL, 2020a). Além disso, conforme já mencionado anteriormente, a pecuária catarinense sofreu grandes modificações ao longo das últimas décadas, com a adoção de padrões técnicos mais elevados e ampliação do rebanho ${ }^{5}$. Nessa conjuntura, a participação do autoconsumo no total de animais abatidos no estado passou de 17,70\%, em 2010, para 13,52\%, em 2019, menor índice dessa série histórica.

Para fins de comparação, Miranda e Zen (2019) relatam que 7,42\% dos bovinos abatidos no país em 2015 tiveram como finalidade o autoconsumo, o qual foi responsável por $9,30 \%$ da carne bovina consumida no país naquele ano. Contudo, os autores apontam a existência de variações regionais significativas, citando os casos de Rondônia (48,2\% do consumo proveniente do abate para autoconsumo), Mato Grosso $(39,0 \%)$ e Pará $(14,1 \%)$. As principais razões para esses elevados percentuais seriam a má qualidade das estradas e a distância das fazendas até os centros de consumo. Outro estado mencionado pelos autores é o Rio Grande do Sul, onde 232,6 mil bovinos foram abatidos para autoconsumo, equivalente a $11,32 \%$ da produção total do estado em 2015. Como é possível perceber, os percentuais registrados em Santa Catarina aproximam-se dos índices levantados por Zen e Miranda.

Figura 2 - Participação do autoconsumo no total de abates - Santa Catarina - 2010/2019

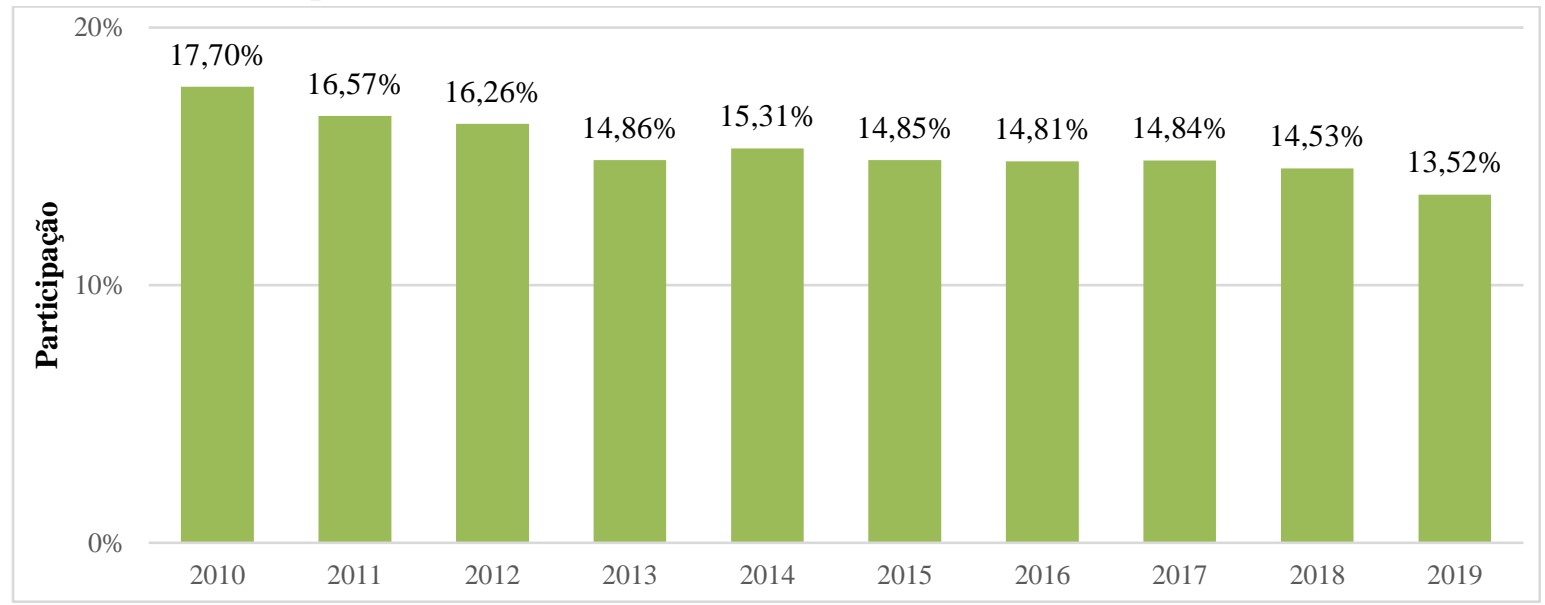

Fonte: Elaborado pelos autores, a partir de dados da Cidasc.

\footnotetext{
5 As transformações da pecuária catarinense necessitam ser mais bem estudadas e compreendidas, principalmente no que diz respeito às mudanças no perfil dos produtores e na geografia da produção, o que se constitui num desafio aos pesquisadores da área.
} 
Ao analisar o sexo dos bovinos destinados ao autoconsumo, verifica-se a predominância de machos, o que é esperado, já que grande parte dos produtores retém as fêmeas para a obtenção de novas crias e/ou para a produção de leite. Contudo, nos últimos anos registra-se aumento da participação das fêmeas no total. Esse processo costuma ocorrer em períodos de estagnação dos preços pagos ao produtor, situação observada até o último trimestre de 2019, o que desestimula a retenção de fêmeas por parte dos pecuaristas ${ }^{6}$. Conforme demonstra a Figura 3, a participação de machos cresceu de 2010 a 2013. Nos anos seguintes, houve uma progressiva queda, até que se atingisse o menor patamar em 2019.

Estudos preliminares apontam uma relação entre as variações no preço pago ao produtor pelo leite e o abate de fêmeas. Quando os preços do leite permanecem longos períodos em patamares considerados baixos pelos produtores, a tendência é que as vacas menos produtivas ou que apresentam problemas reprodutivos sejam destinadas ao abate (em frigoríficos ou no próprio estabelecimento rural), além de se reduzir a incorporação de novilhas ao plantel. Essa situação é mais perceptível nas regiões em que a produção de leite tem relevância econômica, como é o caso de Santa Catarina, $4^{\circ}$ principal produtor do país.

Figura 3 - Abate de bovinos para autoconsumo, por sexo - Santa Catarina - 2010/2019

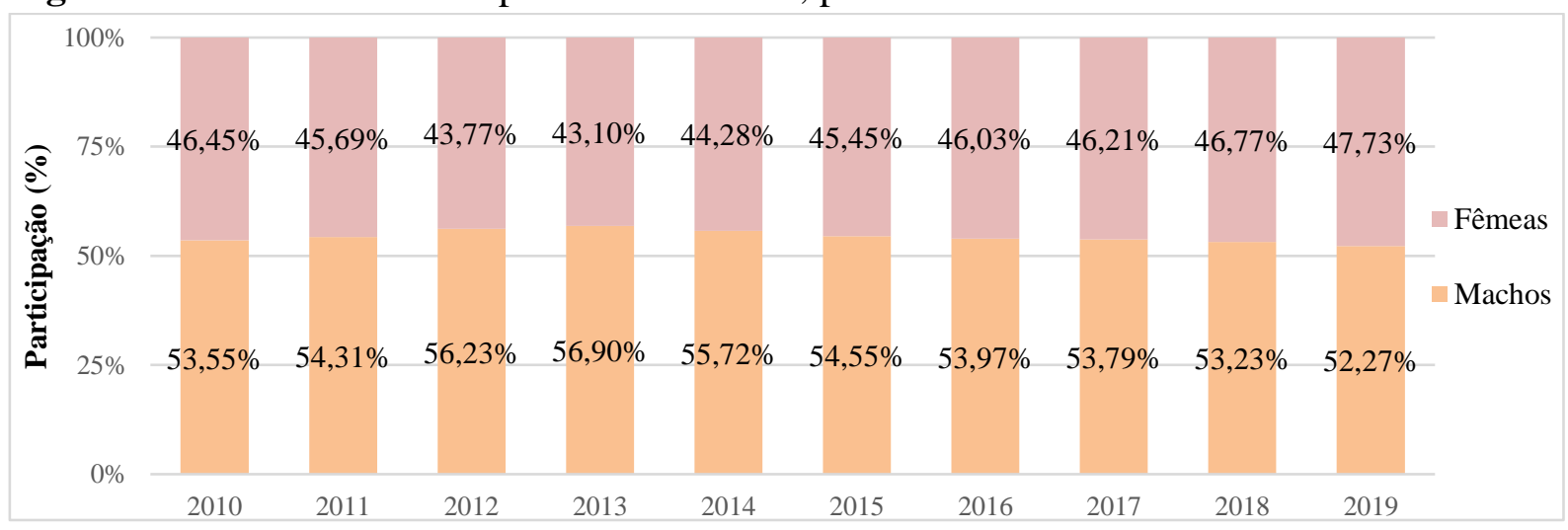

Fonte: Elaborado pelos autores, a partir de dados da Cidasc.

Nesse sentido, Zen, Mariana e Grigol (2018) afirmam que o maior descarte de vacas leiteiras nos últimos anos se deve à crise no setor, que resultou em quedas drásticas nos preços do leite a partir de meados de 2017. Esse cenário manteve-se até o início de 2020, sendo bastante provável sua influência nos resultados apresentados na Figura 3, não obstante a necessidade de estudos complementares.

\footnotetext{
${ }^{6}$ Para maiores informações sobre esse assunto, consultar Giehl (2020b), Lima Filho et al. (2018), entre outros. DOI: http://dx.doi.org/10.22295/grifos.v30i54.5936 | Edição Vol. 30, Núm. 54, 2021. 
No caso dos abates inspecionados, os dados do IBGE (2020) demonstram a ocorrência de situação semelhante nos últimos anos. Em 2010, os machos representavam 62,44\% dos abates realizados nos frigoríficos de Santa Catarina, contra 37,56\% de fêmeas. Nos anos seguintes, registrou-se um progressivo crescimento da participação de fêmeas, até se atingir $48,35 \%$ em 2019. Em termos nacionais, a variação foi menor, mas também causou alguns impactos no mercado de carnes. Em 2010, eram 63,83\% de machos e 36,10\% de fêmeas, índices que passaram para 59,24\% e 40,76\%, respectivamente, em 2019.

Outra análise relevante elaborada no presente artigo diz respeito à idade de abate dos bovinos destinados ao autoconsumo. Os animais foram agrupados em 4 faixas etárias: 0 a 12 meses; 13 a 24 meses; 25 a 36 meses; acima de 36 meses. A categoria mais expressiva é formada pelos animais com mais de 36 meses que, na média dos dez anos, representou 36,37\% do total. De acordo com Bortoluzzo, Pedrinola e Martins (2011), considerando-se estritamente o critério econômico, a idade ideal para o abate de bovinos de corte é de 2,2 anos. Do ponto de vista de qualidade da carne, é recomendável o abate entre 2 e 3 anos de idade. Trabalho desenvolvido por Cucco et al. (2015) demonstra que a idade média de abate nos principais frigoríficos de Santa Catarina é de 2,5 anos.

Tal cenário demonstra que mais de 1/3 do autoconsumo é suprido com bovinos acima da idade ideal de abate. Em geral, esses animais possuíam outra finalidade (produção de leite, reprodução, tração, etc.) e, com o declínio de seu período produtivo, foram destinados ao abate. Essa situação é condizente com a forte presença da atividade leiteira nas propriedades familiares de Santa Catarina.

Conforme evidencia a Figura 4, a participação dos animais com mais de 36 meses apresenta tendência de crescimento ao longo do período analisado. Vale mencionar que os consumidores normalmente preferem carne de animais mais jovens e criados especificamente para o abate, o que resulta em pouco interesse por parte dos frigoríficos em bovinos com idades mais avançadas e, principalmente, em vacas leiteiras. Assim, o autoconsumo pode se constituir numa opção economicamente mais interessante para a destinação desses animais ou, por vezes, na única alternativa disponível. 
Figura 4 - Abate de bovinos para autoconsumo, por idade - Santa Catarina - 2010/2019

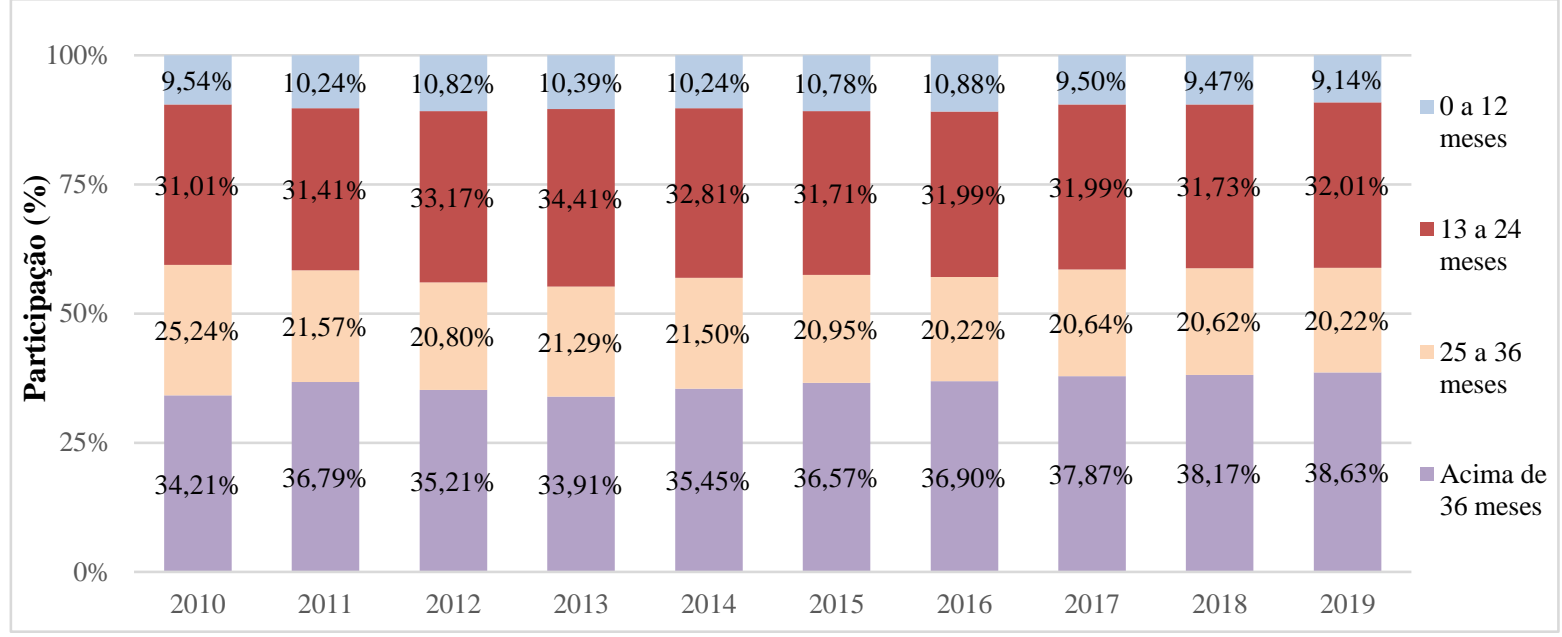

Fonte: Elaborado pelos autores, a partir de dados da Cidasc.

A segunda categoria mais numerosa é a dos animais abatidos com 13 a 24 meses de idade (novilhos ou novilhas), que reúne 32,22\% dos abates realizados entre 2010 e 2019, mantendo sua participação relativamente estável ao longo do período analisado. No caso dos produtores de leite, os machos nascidos na propriedade normalmente são vendidos, doados ou, em alguns casos, criados para consumo da família. Nessas situações, é comum que os animais sejam abatidos ainda jovens, já que, por serem de raças com aptidão leiteira, o baixo ganho de peso e as características corpóreas desestimulam a manutenção até a idade adulta.

A terceira categoria é formada pelos animais abatidos com idade entre 25 e 36 meses, com participação média de $21,31 \%$ ao longo dos dez anos. Percebe-se uma queda na participação dessa faixa etária no total de abates.

Por fim, embora seja a categoria menos numerosa, chama atenção o expressivo percentual de animais abatidos com até 12 meses, cuja participação manteve-se relativamente estável ao longo de todo o período. Mais uma vez, grande parte desses abates provavelmente são de animais de raças com aptidão leiteira e baixo ganho de peso, o que torna sua criação para fins de corte economicamente desinteressante. Por isso, os machos nascidos de vacas leiteiras são, muitas vezes, simplesmente sacrificados nos primeiros dias de vida. Essa situação demanda especial atenção do setor, tendo em vista o crescente nível de preocupação dos consumidores em relação aos produtos que consomem. 
No presente estudo também se identificou a distribuição dos abates nas seis mesorregiões de Santa Catarina. Os dados demonstram que, no ano de 2019, mais de 2/3 dos abates para consumo próprio ocorreram na Mesorregião Oeste Catarinense (Figura 6).

Figura 5 - Mesorregiões de Santa Catarina, de acordo com classificação do IBGE.

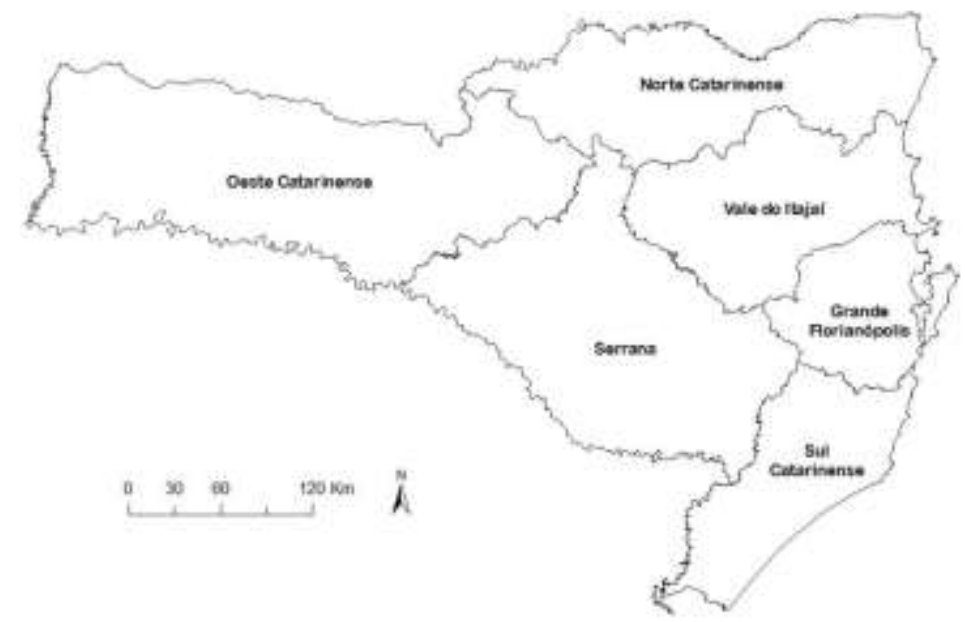

Fonte: IBGE.

Por outro lado, em 2019 o Oeste Catarinense respondia por 47,40\% do rebanho total do estado. Ou seja, a participação dessa mesorregião na produção para autoconsumo supera sua representatividade no rebanho estadual. Há duas explicações para essa situação. A primeira diz respeito à configuração fundiária e social dos espaços rurais da região, com forte predomínio da produção familiar. A relação entre agricultura familiar e produção para autoconsumo é evidenciada por diversos autores. Fontoura (2012), por exemplo, ressalta que, no caso do Rio Grande do Sul, estudos mostram que as regiões com maior expressividade dessa estratégia produtiva são aquelas em que o ethos de colono se mantém presente de maneira mais significativa. Não obstante as transformações na estrutura fundiária e produtiva observadas nas últimas décadas, situação semelhante é observada no Oeste Catarinense. 
Figura 6 - Abate de bovinos para autoconsumo, por mesorregião - Santa Catarina 2010/2019

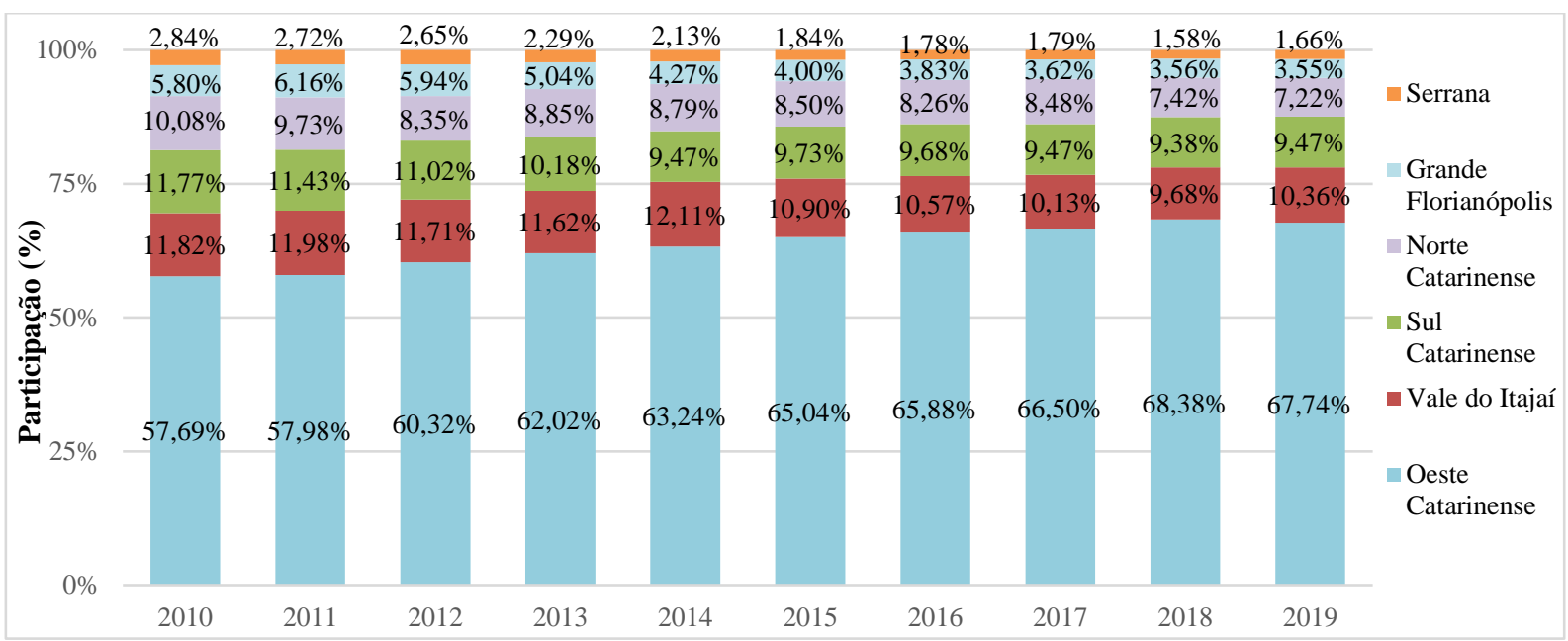

Fonte: Elaborado pelos autores, a partir de dados da Cidasc.

O segundo fator é a expressiva presença da pecuária leiteira. O Oeste Catarinense é a principal "bacia leiteira" do estado, responsável por 79,1\%da produção em 2017 (MARCONDES, 2018). Como já mencionado, a produção leiteira tem como "subproduto" o nascimento de bezerros machos que, por não serem de raças com aptidão para o corte, dificilmente entram no circuito comercial da produção de carnes. Além disso, outro "subproduto" da pecuária leiteira são as fêmeas em declínio produtivo, seja pela idade, seja pela ocorrência de doenças, o que leva à sua exclusão do plantel. Esses animais têm valor comercial menor que bovinos jovens, com aptidão específica para corte ou condição corporal mais adequada para o abate. Em função disso, por vezes torna-se vantajoso ao produtor abatêlos para atender a demanda de consumo da família, ao invés de comercializá-los.

A participação do Oeste Catarinense no total estadual cresceu significativamente entre 2010 e 2019, como evidencia a Figura 6. Outras mesorregiões que também apresentam participação relevante no total do estado são o Vale do Itajaí e o Sul Catarinense, com 10,36\% e 9,47\% dos abates realizados em 2019, respectivamente. Em ambos os casos, há também uma presença expressiva de agricultores familiares nessas duas regiões, bem como relevância da produção de leite.

Outro aspecto analisado no presente trabalho é a sazonalidade. Para tanto, identificouse o número de abates para autoconsumo registrados mensalmente e calculou-se a participação de cada mês no total anual. A Figura 7 apresenta a média mensal dos abates realizados no período de 2010 a 2019. Conforme fica evidenciado, há um relativo equilíbrio 
ao longo do ano, com exceção de dezembro, cujo índice é quase o dobro dos demais meses. Essa concentração condiz com a vivência e a percepção empírica dos autores, já que os abates para autoconsumo, além de atenderem a demanda alimentar cotidiana, têm também um objetivo mais lúdico, que é possibilitar confraternizações familiares nas festividades de final de ano, em especial o Natal. Esse é um dos principais fatores que explicam essa concentração em dezembro.

Figura 7 - Distribuição mensal do abate de bovinos para autoconsumo - Santa Catarina período 2010-2019

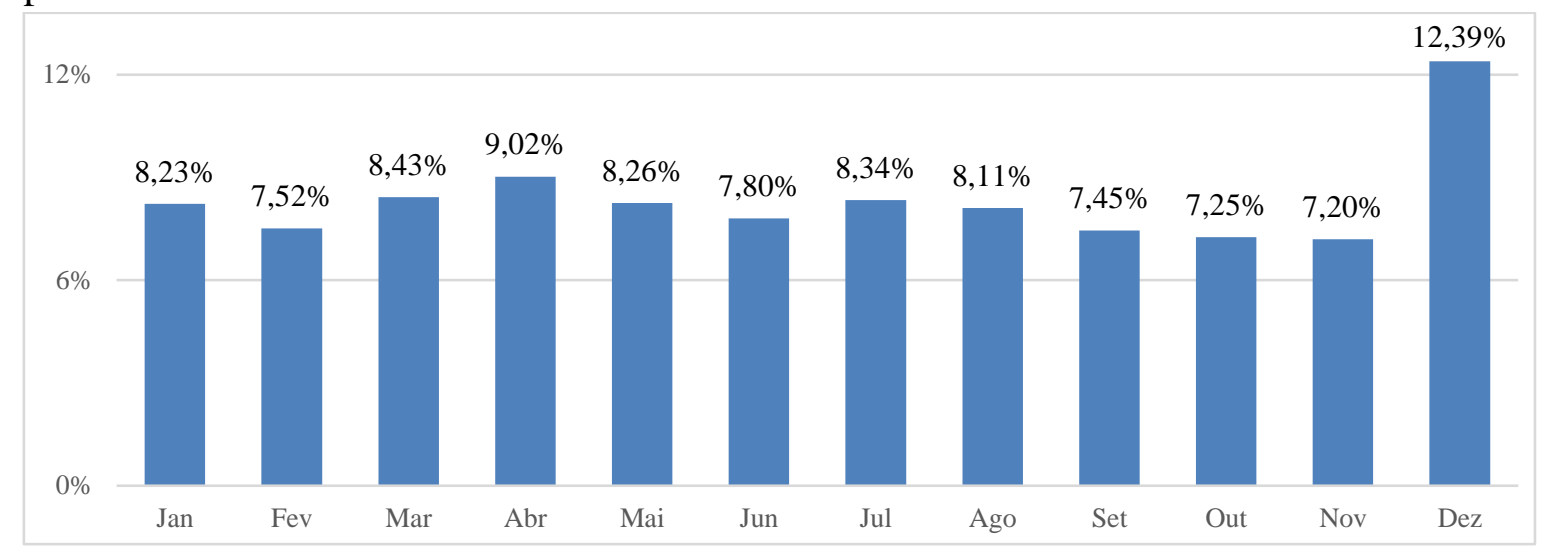

Fonte: Elaborado pelos autores, a partir de dados da Cidasc.

Segundo Menasche, Marques e Zanetti (2008), as escolhas alimentares que os agricultores fazem são perpassadas por aspectos simbólicos, sendo as "comidas de festa" consideradas particularmente emblemáticas nesse sentido. Embora as autoras, ao tratar desse tema, estejam se referindo mais especificamente às festas comunitárias, podemos extrapolar o raciocínio para o caso das festividades de final de ano, que costumam reunir grande parte da família, inclusive filhos ou outros membros que residem fora da propriedade rural.

Nesse mesmo estudo, as autoras fazem menção à importância da carne, principalmente bovina, como um elemento que explicita a ruptura com uma época de carências acentuadas, em que o consumo desse alimento era pouco frequente. Se, por um lado, os relatos dos agricultores entrevistados remetem a um passado de escassez ("porque nós, às vezes, esperava seis meses pra poder comer um churrasco, quando era convidado para um casamento, uma coisa assim, né”), por outro, as falas em relação ao presente reforçam a noção de fartura ("aqui, ninguém sabe fazer comida sem um pedaço de carne").

Os tradicionais almoços familiares de Natal ou Ano-Novo, que em grande parte da Região Sul comumente têm como prato principal o churrasco, podem ser também uma forma DOI: http://dx.doi.org/10.22295/grifos.v30i54.5936 | Edição Vol. 30, Núm. 54, 2021. 
de celebração do progresso material. Em razão disso, é recorrente que o agricultor escolha um ou mais animais a serem abatidos em tais ocasiões.

Segundo Ploeg (2003, apud GRISA; SCHNEIDER, 2008), um dos fatores que interferem nas decisões relativas ao autoconsumo é o repertório cultural, que pode ser definido como um conjunto de noções estratégicas que guiam as ações práticas e o comportamento dos agricultores. Nesse contexto, é possível afirmar que as celebrações familiares em determinadas datas festivas e a presença da carne bovina no cardápio são componentes do repertório cultural desses sujeitos.

Ainda em relação aos resultados apresentados na Figura 7, chama atenção o fato de abril ser o segundo principal mês em termos de concentração de abates, considerada a média dos dez anos, seguido por março. Ao recorrer ao calendário, observou-se que, de 2010 a 2019, a Páscoa foi celebrada no mês de abril em oito ocasiões. Em quase todas elas, abril concentrou o segundo maior volume de abates do ano. Em 2013, quando a Páscoa foi celebrada no dia 31 de março, este mês registrou o segundo maior volume de abates para autoconsumo do ano (8,55\%), atrás apenas de dezembro (13,56\%). Abril, por sua vez, foi apenas o $8^{\circ}$ no ranking, com 7,89\% dos abates daquele ano. Da mesma forma, em 2016, quando a Páscoa foi celebrada no dia 27 de março, este mês registrou o segundo maior volume de abates do ano (9,55\% do total), enquanto abril foi o mês com a menor participação (7,23\%). A distribuição mensal dos abates é apresentada na Tabela 2.

Tabela 2 - Distribuição mensal dos abates de bovinos para autoconsumo - Santa Catarina 2010/2019

\begin{tabular}{ccccccccccccc}
\hline Ano/mês & Jan & Fev & Mar & Abr & Mai & Jun & Jul & Ago & Set & Out & Nov & Dez \\
\hline 2010 & 7,42 & 7,08 & 8,28 & 8,46 & 7,75 & 7,79 & 8,27 & 8,15 & 7,92 & 7,52 & 7,58 & 13,76 \\
2011 & 7,74 & 7,66 & 7,71 & 9,76 & 7,95 & 7,49 & 7,47 & 7,57 & 7,09 & 7,44 & 7,78 & 14,34 \\
2012 & 7,89 & 7,60 & 8,11 & 9,96 & 8,70 & 7,69 & 7,45 & 7,56 & 7,28 & 7,45 & 7,38 & 12,94 \\
2013 & 7,83 & 6,97 & 8,55 & 7,89 & 8,02 & 7,46 & 8,17 & 8,11 & 7,98 & 8,18 & 7,29 & 13,56 \\
2014 & 8,19 & 7,28 & 7,71 & 9,25 & 7,44 & 7,05 & 8,20 & 7,81 & 7,99 & 7,90 & 7,56 & 13,60 \\
2015 & 8,07 & 7,49 & 8,55 & 8,59 & 7,71 & 7,67 & 7,83 & 7,57 & 7,92 & 7,32 & 7,85 & 13,42 \\
2016 & 8,40 & 8,09 & 9,22 & 7,23 & 8,04 & 7,68 & 7,71 & 8,04 & 7,92 & 7,24 & 7,72 & 12,71 \\
2017 & 8,09 & 7,00 & 7,82 & 8,56 & 8,70 & 7,23 & 7,89 & 8,31 & 7,66 & 8,08 & 7,76 & 12,89 \\
2018 & 7,87 & 6,85 & 8,02 & 7,54 & 7,81 & 7,47 & 8,91 & 8,59 & 7,80 & 8,13 & 8,12 & 12,90 \\
2019 & 8,48 & 7,41 & 7,58 & 9,66 & 8,17 & 7,80 & 8,64 & 8,20 & 8,33 & 7,94 & 7,31 & 10,49 \\
\hline
\end{tabular}

Fonte: Elaborado pelos autores, a partir de dados da Cidasc.

Embora não seja possível afirmar de forma conclusiva, os dados anteriores sugerem uma relação entre a celebração da Páscoa e o abate de bovinos para autoconsumo. Assim DOI: http://dx.doi.org/10.22295/grifos.v30i54.5936 | Edição Vol. 30, Núm. 54, 2021. 
como o Natal, a Páscoa também é caracterizada por ser, tradicionalmente, uma celebração em família. Além disso, na tradição da Igreja Católica, a Sexta-Feira Santa é um dia reservado para a prática da abstinência, sendo vedado o consumo de carne nessa data. Por outro lado, o domingo de Páscoa é, de certa forma, um "retorno da fartura” (simbólica e prática), muitas vezes caracterizada por almoços fartos, tendo o churrasco como um dos pratos principais.

Conforme evidenciam os dados apresentados na Tabela 1, em 2019 houve uma queda de $2,52 \%$ em relação ao ano anterior no número de bovinos destinados ao autoconsumo. Grande parte dessa diferença concentra-se nos três últimos meses do ano, em especial dezembro, quando foram abatidos 2,6 mil bovinos a menos que no mesmo mês de 2018.

Uma explicação para essa queda parece estar na significativa elevação dos preços da carne bovina e, por consequência, do animal vivo, observada no último trimestre de 2019, conforme detalhado em Giehl (2020a).

De acordo com diversos autores (GARCIA JUNIOR, 1983, 1989; e HEREDIA, 1979; apud GRISA; SCHNEIDER; CONTERATO, 2013), uma das importantes marcas da produção para autoconsumo é a alternatividade, que consiste na capacidade de se optar tanto pelo consumo como pela transformação dos produtos em valores de troca, conforme a demanda da família, as condições de preço, a perecibilidade, entre outros elementos.

Essa característica aparentemente se fez presente no caso mencionado, levando parte dos agricultores a preferir a venda dos bovinos que seriam consumidos, visto que os preços eram compensatórios, com altas de até 36\% em relação ao ano anterior (GIEHL, 2020a). Os valores mais elevados pagos pelos frigoríficos no último trimestre de 2019 foram registrados justamente em dezembro, período em que, tradicionalmente, se concentram os abates para autoconsumo. Assim, a coincidência entre a disponibilidade de animais prontos para abate e os preços atrativos levou muitos produtores a fazer uso da alternatividade. Tal argumentação é reforçada por outro dado apresentado neste estudo: em 2019, registrou-se a menor participação do mês de dezembro no total de abates no período analisado (10,49\%).

Essa perspectiva é corroborada por Fontoura (2012), ao afirmar que, no caso dos pecuaristas familiares, a produção para o autoconsumo e a venda de parte do gado em momentos que o mercado se apresente favorável ou haja necessidade de recursos financeiros, consistem nas principais estratégias de reprodução social desse segmento. 


\section{CONSIDERAÇÕES FINAIS}

Embora a produção para autoconsumo tenha merecido atenção da academia nas duas últimas décadas, o mesmo não pode ser dito da produção animal com a mesma finalidade, em especial na realidade de Santa Catarina. Poucos são os estudos que abordam tal temática, o que contribui para o desconhecimento de sua relevância econômica e social. Nesse sentido, o presente trabalho se propôs a analisar diversos aspectos da produção catarinense de bovinos para autoconsumo, bem como dimensionar alguns fatores associados a essa atividade.

Em termos econômicos, demonstrou-se que o valor bruto da produção decorrente dessa modalidade foi de R $\$ 223$ milhões no ano de 2019. Considerada individualmente, seria a $15^{\mathrm{a}}$ principal atividade agropecuária do estado. Em relação à abrangência, identificaram-se 50,6 mil produtores que realizaram o abate para autoconsumo no ano de 2019, o que representa $27,6 \%$ do total de estabelecimentos existentes no estado. Para fins de comparação, esse número é significativamente superior ao de produtores de suínos (7,5 mil) e frangos (5,9 mil), as duas principais atividades econômicas da agropecuária catarinense, superando também o número de produtores que destinaram bovinos para abate em frigoríficos inspecionados $(36,4$ mil).

Não obstante sua aparente oposição e independência em relação à pecuária comercial, o presente artigo evidenciou que a produção para autoconsumo é influenciada de diversas maneiras pelo mercado. As altas nos preços da carne bovina no último trimestre de 2019, por exemplo, impactaram no número de bovinos abatidos para consumo próprio nesse período, em função de uma característica intrínseca ao autoconsumo, denominada alternatividade. Outro fator relacionado ao mercado que também se mostrou potencialmente capaz de afetar o autoconsumo é o preço do leite, principalmente levando em consideração que essa é uma atividade muito presente nas propriedades familiares do Oeste Catarinense.

Embora seja possível perceber relações entre a produção de bovinos para autoconsumo e essas duas dimensões do mercado, são necessárias análises mais aprofundadas para a compreensão do tipo e do grau de influência exercida, as quais fogem do escopo deste trabalho, razão pela qual sugere-se a realização de novos estudos com tal finalidade.

O presente artigo também trouxe à tona a provável relação entre o autoconsumo e os momentos festivos ou de reunião familiar, como é o caso do Natal e da Páscoa, quando foram registradas elevações no número de animais abatidos, em comparação aos demais períodos 
do ano. Nesse sentido, concorda-se com Grisa (2007) quando a autora afirma que a produção para consumo familiar está imbricada num complexo conjunto de elementos e relações objetivas e subjetivas, muito além da simples aversão ao mercado ou ao trabalho.

Outra questão levantada no decorrer deste trabalho e que demanda estudos complementares para ser adequadamente compreendida é o impacto das mudanças demográficas no meio rural sobre a produção de bovinos para autoconsumo. Embora alguns autores apontem a relação entre esses dois fatores em diversos estudos de caso, uma análise mais ampla da realidade estadual, partindo dos dados utilizados no presente artigo e confrontando-os com informações demográficas, é, não apenas relevante, como necessária.

Por fim, consideramos que o presente artigo, longe de esgotar o debate, lançou luz sobre algumas características e dinâmicas associadas a essa estratégia de reprodução social que segue sendo importante, não obstante as transformações observadas no meio rural em período recentes. Assim, novos estudos são necessários para cobrir as lacunas decorrentes da escassa atenção direcionada a esse tema nos últimos anos.

\section{REFERÊNCIAS}

BORTOLUZZO, A.B.; PEDRINOLA, P.D.; MARTINS, S.R. Tempo ideal para abate de gado de corte via maximização do lucro. São Paulo: Insper, 2011.

CUCCO, D.C. et al. Perfil dos bovinos abatidos pelos principais abatedouros/ frigoríficos do estado de Santa Catarina. In: Simpósio Internacional sobre Sistemas de Produção de Bovinos de Corte, II, 2015, Porto Alegre. Anais... [...]. Porto Alegre: UFRGS, 2015.

DORIGON, C. et al. A produção de alimentos para o autoconsumo na região oeste do Estado de Santa Catarina. In: Redes (Santa Cruz Sul, Online), v. 25, p. 2060-2085, 2020.

FACHIN, G.B. Cadeia produtiva da carne em Santa Catarina. 2014. 94f. Monografia de conclusão de curso (Zootecnia), UFSC, Florianópolis, 2014.

FONTOURA, A.F. A produção para autoconsumo: características e importância para os sistemas de produção de pecuária familiar da fronteira oeste do RS. 2012. 152f. Dissertação (Mestrado em Extensão Rural) - Programa de Pós-Graduação em Extensão Rural, Universidade Federal de Santa Maria, Santa Maria, 2012.

GAZOLLA, M. Agricultura familiar, segurança alimentar e políticas públicas: uma análise a partir da produção para autoconsumo no território do Alto Uruguai/RS. 2004. 287f. Dissertação (Mestrado em Desenvolvimento Rural) - PGDR/UFRGS, Porto Alegre, 2004.

GIEHL, A.L. Cálculo do Valor Bruto da Produção de carnes em Santa Catarina

(2018). Relatório de projeto - Epagri. Não publicado, 2018. 
GIEHL, A.L.; MONDARDO, M. Caracterização e dinâmica do abate de bovinos em Santa Catarina (2013/2018). In: Congresso da SOBER, 57º 2019, Ilhéus, BA. Anais... [...]. Brasília: SOBER, 2019.

GIEHL, A.L. et al. Participação da agricultura familiar na produção de bovinos em Santa Catarina. In: Encontro da Rede de Estudos Rurais, 8 , 2018, Florianópolis. Anais...[...]. Florianópolis: UFSC, 2019. p. 1.840-1.854.

GIEHL, A.L. Carne bovina. In: Síntese Anual da Agricultura de Santa Catarina 20182019. V. 1 - Florianópolis: Epagri, 2020a.

GIEHL, A.L. Bovinocultura. In: EPAGRI/CEPA. Boletim Agropecuário. Janeiro/2020. Florianópolis, 2020b, 57p. (Epagri. Documentos, 303).

GRISA, C. A produção "pro gasto": um estudo comparativo do autoconsumo no Rio Grande do Sul. 2007. Dissertação (Mestrado) - Programa de Pós-Graduação em Desenvolvimento Rural, Universidade Federal do Rio Grande do Sul, Porto Alegre, 2007.

GRISA, C.; SCHNEIDER, S. Fatores determinantes da produção para autoconsumo na agricultura familiar: um estudo comparativo no Rio Grande do Sul. In: Revista de Ciências Sociais, v. 17, n. 2, São Carlos, SP, 2008.

GRISA, C.; CONTERATO, M.A. A produção para o autoconsumo no Brasil: entre a importância econômica e o reconhecimento social. In: Congresso da SOBER, 49 ${ }^{\circ}, 2011$, Belo Horizonte, MG. Anais... [...]. Brasília: SOBER, 2011.

GRISA, C.; SCHNEIDER, S.; CONTERATO, M.A. A produção para autoconsumo no Brasil: uma análise a partir do Censo Agropecuário 2006. Brasília: IPEA, 2013.

IBGE. Instituto Brasileiro de Geografia e Estatística. Sistema IBGE de Recuperação Automática. Disponível em: 〈https://sidra.ibge.gov.br>. Acesso em: 01 abr. 2020.

LIMA FILHO, R.R. et al. Expectativas para o mercado em 2018. AgroAnalysis, v. 38, n. 01, p. 22-23, 2018.

LOVISOLO, H.R. Terra, trabalho e capital: produção familiar e acumulação. Campinas: Editora da Unicamp, 1989.

MAPA. Ministério da Agricultura, Pecuária e Abastecimento. Valor Bruto da Produção Agropecuária (VBP). 2019. Disponível em: <www.agricultura.gov.br/assuntos/politicaagricola/valor-bruto-da-producao-agropecuaria-vbp>. Acesso em: 19 fev. 2020.

MARCONDES, T. Leite. In: Síntese Anual da Agricultura de Santa Catarina 20172018. V. 1 - Florianópolis: Epagri/Cepa, 2018.

MATTE, A.; WAQUIL, P.D. Vulnerabilidade social e a construção de estratégias de enfrentamento e adaptação para pecuaristas de corte no Rio Grande do Sul.

Desenvolvimento e Meio Ambiente, v. 28, 2013.

MENASCHE, R.; MARQUES, F.C.; ZANETTI, C. Autoconsumo e segurança alimentar: a agricultura familiar a partir dos saberes e práticas da alimentação. In: Revista de Nutrição, Campinas, v. 21, supl. p. 145-158, ago. 2008.

MIRANDA, S.; ZEN, S. (coord.). Estudo sobre abate não fiscalizado no setor da pecuária de corte na região amazônica. Piracicaba: Cepea - Esalq/USP, 2019. 
SANTOS, O.V.; MARCONDES, T.; CORDEIRO, J.L.F. Estudo da cadeia do leite em Santa Catarina: Prospecção e demandas. Florianópolis: Epagri, 2006. 55p.

TORESAN, L. et al. M. Indicadores de desempenho da agropecuária e do agronegócio de Santa Catarina: 2018 e 2019. Florianópolis: Epagri, 2019. 67p. (Boletim Técnico n.191).

WEDEKIN, I. Economia da pecuária de corte: fundamentos e o ciclo de preços. São Paulo: Wedekin Consultores, 2017.

ZEN, S.; MARIANO, C.; GRIGOL, N. Abate de vacas leiteiras e sua influência no preço da arroba. In: Revista DBO, São Paulo, n. 449, p. 20, mar. 2018. 